\title{
The Influence of Regional Resident Human Capital Investment on Income Gap
}

\author{
Based on the perspective of population migration \\ Ding Mingfei ${ }^{1, a}$, Pei Jinsong ${ }^{1, b}$ \\ ${ }^{1}$ Beijing Jiaotong University \\ School of Economics and Management \\ Beijing, China
}

\begin{abstract}
With the development of China's economic level and transportation, China's population migration scale is constantly enhanced, population migration investment way of human capital investment, has a greater impact on the income level of residents. This paper analyzes the mechanism of population migration's influence on the income gap and research achievements of predecessors, then on the basis of the eight regional division, has analyzed china area ask migration scale and the present situation of the income gap, and finally by constructing panel data model, the empirical test population migration's influence on regional smell of resident's income gap. Finally, it is found that investment in population migration has a long-term positive effect on the income gap.
\end{abstract}

\section{Introduction}

Since the reform and opening up, China's economic development has made tremendous achievements, but the issue of residents' income gap has always been a hot issue. According to data released by the National Bureau of Statistics in recent years, China's Gini coefficient hovered between 0.462-0.491 between 2003 and 2016, and it belongs to a country with a large income gap. From a spatial perspective, in 2016, the provinces and cities with the highest per capita disposable income of residents in various regions of the country were concentrated in the eastern coastal area, while the lowest provinces and cities were concentrated in the northwest and southwest regions. Among them, the highest per capita disposable income of residents in Shanghai is 54305.35 yuan, and the lowest in Tibet is only 13639.24 yuan, which is only slightly higher than a quarter of Shanghai. The income gap can be seen. The continuation and expansion of the regional income gap is not only not conducive to the efficiency of economic development, but also not conducive to social harmony and affects the process of socialist construction.

Since the birth of human capital theory, it has been applied in many fields and formed new disciplines with many disciplines. Human capital theory has been widely applied to income distribution theory, and human capital investment is considered to be an important factor affecting residents' income gap. The investment in human capital will directly increase the level of human capital of the residents, thereby increasing the income level of the residents, but it will also increase the income gap of the residents. The famous economist Schultz believes that migration investment is an important part of human capital investment, but because its investment costs and benefits are not easy to measure, scholars often do not get too much attention [1]. According to data from the
National Health Commission, the size of China's migrant population increased from 6.57 million in 1982 to 244 million in 2017. From the perspective of the number of residents, the total amount of human resources in China is very large, but it is easy to find that the level of human capital in China is not high and the regional distribution is extremely unbalanced. The human capital of residents in the eastern coastal areas is far ahead of the inland regions in the west in terms of stock and quality. This not only breaks the balance of economic development in China's regions, but also leads to the gap in income levels among residents in regions.

\section{Theoretical framework and literature review}

Population migration refers to the geographical or spatial movement of population between two regions. This kind of movement usually involves the change of permanent residence from the place of immigration to the place of immigration. This article adopts the definition of migration by the National Bureau of Statistics of the People's Republic of China, that is, the separation of people and households, the inhabitation of the town and the street where the residence is registered and the place of residence registration are inconsistent and more than half a year after leaving the place of residence registration. Combining the mechanism of human capital investment in regional human income gap in modern human capital theory, residents in high-income regions have the opportunity and ability to make more investments in population migration, so that residents can often obtain higher levels of knowledge and skills. So as to have a higher level of human capital, and ultimately get a higher income. On the contrary, residents in low-income regions have made relatively little investment in population migration, and their knowledge and skills are at a relatively low level, resulting in a much lower human

acankaodaan123@126.com bjspei@bjtu.edu.cn 
capital stock than residents in high-income regions. A relatively low level of monetary income. In addition, in the cyclical transformation of population migration investment and residents' income distribution, there is a Matthew effect that promotes the widening regional income gap. On the one hand, because the residents in low-income areas are in a state of very low monetary income and less investment in population migration investment, individuals will be at a low level of human capital, with fewer job opportunities, less working space, or even unemployment. Naturally, income is low, which will allow residents in low-income areas to enter a vicious circle of "poor people getting poorer" with low levels of human capital investment; on the other hand, residents in high-income areas have relatively high incomes and have more Strong population migration investment strength, which can raise human capital to a higher level, can obtain more job selection opportunities, enter higher work fields, and finally obtain higher income, and the ability to invest in human capital circulation will also become more Strong, the result is that residents in high-income areas can enter a virtuous cycle of "the rich get richer".

Foreign scholars have conducted a lot of research. Miyagiwa pointed out that the accumulation of human capital is an important factor affecting economic growth, and analyzed the impact of different levels of labor on economic development [2]. The migration of high-skilled labor has caused the loss of talent in less-developed regions and reduced labor productivity and economic growth in these regions speed. After analyzing the data of 31 provinces in China, Whalley believes that the removal of migration barriers will make income inequality disappear [3]. Konstantinos Pouliakas and Deborah Roberts used the CGE model to observe the impact of different types of population migration in Scotland, Greece and Latvia on the local economy [4]. The study found that because these three countries belong to the backward countries in the EU, their technical talents are easy to flow out The difference in wage levels has widened the regional income gap. Lian Qing peng and Sarah Swider found that population migration narrowed the income gap in China. Without this process, the income gap between regions in China will be greater [5].

Based on China's national conditions, domestic scholars have also conducted a lot of research. From the perspective of population and capital mobility, Fan Hongzhong and Li Guoping discussed the impact of various factors such as population migration costs on regional income gaps, and found that population migration costs are the key factors affecting regional income gaps [6]. There are obstacles to population movement, so compared with the actual situation, the regional gap will be relatively reduced. Research by Wang Wei et al. confirmed that labor migration can greatly increase the income level of migrant labor, and it has a positive effect on narrowing the income distribution gap between regions, urban and rural areas, and different demographic characteristics [7]. Zhao Hai and Peng Daiyan used time series data from 1985 to 2007, and found that education investment and migration investment have a significant positive effect on wage income, while health investment has no significant effect on wage income; investment in human capital Among the effects on wage income, education has the largest impact on wage income, followed by migration, and the impact of health investment is negative [8]. Duan Pingzhong believes that the lower the education level of the migrant population in China, the stronger the promotion effect on the regional economic growth rate. The higher the education level of the migrant population, the greater the economic gap between the three major zones, and the greater the regional gap [8]. Shao Yi hang et al. based on the metrological test of China's urban data show that due to the low education level of the migrant labor force, the current labor mobility in China will still widen the income gap within the city, and when the proportion of migrant laborers receiving higher education exceeds half, Labor mobility may narrow the income gap within the city [10].

On the whole, scholars at home and abroad have different views on the impact of migration investment on the income gap. Some support the expansion of the income gap, and some support the reduction of the income gap. This has a greater relationship with the measurement of population migration investment. This paper draws on Guan Ai ping using the transportation and communication costs in the composition of residents' consumption expenditure in the National Statistical Yearbook to measure, combined with the eight regional division methods, to explore the impact of population migration investment on the income gap between residents in China [10].

\section{The current situation of population migration and income gap between regions in China}

\section{A. Migration scale and investment level}

As the market economy system becomes more and more perfect, it provides an institutional basis for the free circulation of individuals, while highly developed communication facilities and transportation infrastructure provide material premises for individual flows. With the liberalization of China's household registration system, the threshold for settlement in developed provinces and cities has become lower and lower, people in order to promote their own better development, obtain higher income levels, obtain a better living and living environment, and provide for their children Due to factors such as the consideration of a generation, more and more people and more and more families choose to migrate.

\section{1) Migration scale}

According to the data of the National Bureau of Statistics, Table I is the table of population migration flow among China's eight major regions ${ }^{1}$ in 2010 . The data in the table is the proportion of the population migrated between regions to the total population migrated between regions. In the 2010 census, the total number of floating population in China was $260,937,942$, among which the floating population among the eight major regions was

${ }^{1}$ With reference to the division method of the National Development Research Center, the mainland China area is divided into eight economic regions. The natural conditions and resource endowments in each of the eight economic regions are similar, the social structure is similar, and they are adjacent to each other in space, which can
better reflect the goal of regional division. The eight major regions are the northern coastal areas (Beijing. Tianjin, better reflect the goal of regional division. The eight major regions are the northern coastal areas (Beijing, Tianjin,
Hebei) And Shandong), the middle reaches of the Yangtze River (Hubei, Hunan, Jiangxi and Anhui), the middle Heaches of the Yellow River (Shanxi, Henan, Shaanxi and Inner Mongolia), the northeast (Liaoning, Jilin and
reacher reaches of the Yellow River (Shanxi, Henan, Shaanxi and Inner Mongolia), the northeast (Liaoning, Jilin and
Heilongjiang), the eastern coastal areas (Shanghai, Jiangsu and Zhejiang), Southern coastal area (Guangdong, Fujian and Hainan), southwest area (Guangxi, Chongqing, Sichuan, Guizhou and Yunnan), northwest area (Gansu, Qinghai, Ningxia, Xinjiang and Tibet). 
$72,401,132$, accounting for $27.75 \%$ of the total floating population. In terms of mobility, the region with the largest population outflow in 2010 was the middle reaches of the Yangtze River, accounting for $383.87 \%$ of the interregional outflow population; the region with the largest population inflow in 2010 was the southern coastal region, accounting for the proportion of interregional inflow population They are $354.18 \%$. From the perspective of flow direction, the most interregional population flow is the middle reaches of the Yangtze
River to the eastern coastal areas, accounting for $174.48 \%$ of the total interregional floating population, followed by the middle reaches of the Yangtze River to the southern coastal areas, accounting for $154.48 \%$ of the total interregional floating population; The region with the least population movement is the northwest region to the northeast region, accounting for $0.45 \%$ of the total interregional population, followed by the northeast region to the northwest region, accounting for $0.78 \%$ of the total interregional population.

TABLE I. CHINA'S POPULATION MIGRATION FLOW BETWEEN REGIONS IN 2010 (\%)

\begin{tabular}{|c|c|c|c|c|c|c|c|c|}
\hline Outflow & $\begin{array}{l}\text { North } \\
\text { Coast }\end{array}$ & northeast & East coast & $\begin{array}{l}\text { Middle } \\
\text { Yellow } \\
\text { River }\end{array}$ & Southern coast & northwest & southwest & $\begin{array}{c}\text { Middle } \\
\text { Yangtze } \\
\text { River }\end{array}$ \\
\hline North Coast & & 31.03 & 10.18 & 42.58 & 4.35 & 5.82 & 14.07 & 25.08 \\
\hline northeast & 5.26 & & 1.95 & 6.83 & 0.81 & 0.45 & 2.19 & 3.32 \\
\hline East coast & 17.13 & 6.66 & & 51.17 & 10.46 & 5.30 & 86.93 & 174.48 \\
\hline $\begin{array}{c}\text { Middle Yellow } \\
\text { River }\end{array}$ & 9.03 & 5.32 & 3.59 & & 1.84 & 5.53 & 6.86 & 7.47 \\
\hline Southern coast & 4.98 & 4.55 & 6.01 & 37.10 & & 2.98 & 144.08 & 154.48 \\
\hline northwest & 2.47 & 0.77 & 2.43 & 11.65 & 0.82 & & 9.94 & 4.51 \\
\hline southwest & 2.72 & 1.53 & 4.09 & 4.66 & 5.76 & 2.20 & & 14.53 \\
\hline $\begin{array}{c}\text { Middle Yangtze } \\
\text { River }\end{array}$ & 2.91 & 1.21 & 5.97 & 7.15 & 4.49 & 1.15 & 9.15 & \\
\hline
\end{tabular}

In 2010, the scale of China's population migration is still relatively large, and the proportion of population migration among regions is relatively high. The coastal area is the main inflow area, and the central area is the main outflow area. The general trend of population flow from the central and western areas to the eastern area has not changed. In addition, it can be seen that location factors and transportation factors are the main factors for people's migration. People tend to migrate to adjacent areas, such as the southwestern region to the southern coastal region, the middle reaches of the Yangtze River to the eastern coastal region, and the northwest and northeast regions because of the distance is far away, the transportation is inconvenient, and the proportion of mutual migration is low.

Table II is the table of population migration flow among China's eight major regions in 2015. In the national $1 \%$ population sampling survey in 2015 , the total number of floating population in China was $4,545,865$, accounting for $21.33 \%$ of the total sampled population, of which 1,281,493 were inter-regional floating population, accounting for $27.9 \%$ of the total floating population, compared with 2010 Basically unchanged. From the perspective of the number of flows, compared with 2010, the three regions with the largest population outflows in 2015 were the middle reaches of the Yangtze River, the southwest, and the middle reaches of the Yellow River. , From $818.21 \%$ o to $781.30 \%$; the three regions with the largest population inflows in 2015 were the southern coastal region, the eastern coastal region and the northern coastal region, which was unchanged from 2010, but the three combined accounted for the interregional The proportion of the total inflow of population dropped from $839.42 \%$ to $807.30 \%$. From the perspective of flow direction, the most inter-regional population flow is still in the middle reaches of the Yangtze River to the eastern coastal areas, the middle reaches of the Yangtze River to the southern coastal areas, and the southwest to the southern coastal areas. There was a decrease; the least interregional population flow was in the order of the southern coastal region to the northeast region, the northwest region to the northeast region, and the northeast region to the northwest region. The sum of the three accounts for only $2.38 \%$ of the total interregional floating population.

\section{2) Resident relocation investment expenditure}

Since the reform and opening up, the economy has continued to prosper and the degree of marketization has continued to deepen. Resident migration investment has also increased. Measuring the level of residents' migration expenditure is a relatively difficult problem, and the existing literature has not established an effective and reliable analysis index. In this paper, the transportation and communication expenditures of per capita consumption in residents 'consumption expenditures of National Statistical Yearbook are used to replace residents' migration investment. According to the abovementioned scale of inhabitants migration, the proportion of inter-regional population migration in China accounts for a relatively stable proportion of the total migration population in China. In 2010, the cross-region migration population accounted for $27.75 \%$ of the national migration population. $27.9 \%$ of the scale, the average value is $27.825 \%$, so the cross-regional migration investment expenditure of residents in this paper is obtained by multiplying the per capita migration expenditure of residents by $27.825 \%$. 
TABLE II. CHINA'S POPULATION MIGRATION FLOW BETWEEN REGIONS IN 2015 (\%o)

\begin{tabular}{|c|c|c|c|c|c|c|c|c|}
\hline Inflow & $\begin{array}{l}\text { North } \\
\text { Coast }\end{array}$ & northeast & East coast & $\begin{array}{c}\text { Middle } \\
\text { Yellow River }\end{array}$ & Southern coast & northwest & southwest & $\begin{array}{c}\text { Middle } \\
\text { Yangtze River }\end{array}$ \\
\hline North Coast & & 29.22 & 10.00 & 43.80 & 4.44 & 6.33 & 14.27 & 23.21 \\
\hline northeast & 4.87 & & 1.46 & 5.63 & 0.73 & 0.77 & 1.90 & 2.47 \\
\hline East coast & 18.95 & 7.45 & & 56.04 & 10.29 & 5.86 & 75.14 & 157.52 \\
\hline $\begin{array}{c}\text { Middle } \\
\text { Yellow River }\end{array}$ & 10.24 & 5.44 & 5.09 & & 3.40 & 6.14 & 4.82 & 7.77 \\
\hline Southern coast & 5.46 & 5.59 & 6.65 & 31.67 & & 2.74 & 141.43 & 151.22 \\
\hline northwest & 2.80 & 0.87 & 2.47 & 10.91 & 0.93 & & 7.28 & 3.89 \\
\hline southwest & 4.20 & 2.06 & 8.31 & 5.68 & 11.77 & 2.73 & & 15.72 \\
\hline $\begin{array}{c}\text { Middle } \\
\text { Yangtze River }\end{array}$ & 5.00 & 1.83 & 12.56 & 9.27 & 9.95 & 2.09 & 11.64 & \\
\hline
\end{tabular}

Data source: According to "China 1\% Population Survey 2015"

TABLE III. COMPARISON OF CROSS-REGIONAL PER CAPITA MIGRATION EXPENDITURE OF RESIDENTS IN VARIOUS REGIONS OF CHINA

\begin{tabular}{|c|c|c|c|c|c|c|c|c|}
\hline year & North Coast & East coast & Southern coast & northeast & northwest & $\begin{array}{c}\text { Middle } \\
\text { Yellow River }\end{array}$ & $\begin{array}{c}\text { Middle } \\
\text { Yangtze River }\end{array}$ & southwest \\
\hline 2005 & 174.51 & 309.80 & 355.69 & 141.02 & 98.26 & 96.17 & 109.63 & 102.78 \\
\hline 2006 & 213.27 & 366.28 & 387.93 & 154.06 & 106.84 & 126.35 & 128.75 & 123.30 \\
\hline 2007 & 244.89 & 415.62 & 475.78 & 181.84 & 125.12 & 149.53 & 146.26 & 140.25 \\
\hline 2008 & 263.24 & 434.07 & 448.54 & 209.77 & 139.65 & 160.99 & 154.36 & 159.82 \\
\hline 2009 & 314.14 & 531.83 & 512.34 & 246.91 & 162.45 & 186.59 & 180.76 & 196.68 \\
\hline 2010 & 394.24 & 611.65 & 601.67 & 288.28 & 189.09 & 233.13 & 220.53 & 240.74 \\
\hline 2011 & 427.15 & 667.08 & 648.75 & 333.46 & 227.31 & 274.22 & 262.75 & 269.01 \\
\hline 2012 & 483.65 & 777.34 & 755.88 & 391.09 & 266.43 & 330.94 & 305.28 & 314.19 \\
\hline 2013 & 511.62 & 834.11 & 617.65 & 467.24 & 326.50 & 365.02 & 367.68 & 354.25 \\
\hline 2014 & 585.31 & 947.96 & 709.19 & 490.13 & 386.87 & 402.47 & 388.56 & 388.90 \\
\hline 2015 & 646.98 & 976.51 & 775.74 & 548.10 & 449.02 & 442.03 & 470.32 & 454.34 \\
\hline 2016 & 718.54 & 1071.91 & 843.75 & 665.15 & 536.34 & 485.33 & 541.33 & 511.27 \\
\hline
\end{tabular}

As can be seen from Table III, due to the marketization of the economy and society, the continuous promotion of urbanization and more diversified travel modes, the migration investment level of residents continues to rise, and the investment intensity of urban and rural areas has diverged. Specifically, in 2005, the area with the highest per capita migration investment was the southern coastal area, with a per capita investment of 355.69 yuan, and the least invested area was the middle reaches of the Yellow River, with a per capita investment of 96.17 yuan, a difference of 259.52 yuan. In 2016, the area with the most residents per capita migration investment was the eastern coastal area, with a per capita investment of 1071.91 yuan, and the least invested was the middle reaches of the Yellow River, with a per capita investment of 485.33 yuan, a difference of 586.58 yuan. In terms of growth rate, from 2005 to 2016, per capita migration investment in the northwest region increased by 438.09 yuan, an increase of 4.46 times, with an average annual increase of $40.53 \%$, the fastest growth; per capita migration investment in the southern coastal region increased by 488.06 yuan, higher than Northwest China, but due to its large base, it has only increased by 1.37 times, with an average annual increase of $12.47 \%$, the slowest growth. Moreover, the average annual growth rate of the three coastal areas is less than $30 \%$, and all other areas are higher than $30 \%$. The gap between per capita migration investment will gradually narrow. It can be concluded that with the changes in the social environment, residents in various regions generally recognize the importance of migration and continue to increase investment in the migration of human capital.

\section{B. The status quo of the income gap among the residents in China}

At present, the main indicators for measuring the regional income gap are: coefficient of variation, Gini coefficient, and Theil index. Theil index can not only measure the total income gap, but also can be decomposed into interval gaps and intra-area gaps, therefore, this section chooses to use the Theil index as an indicator to study the income gap between regions in China. After calculation, the specific results are shown in Table IV. 
TABLE IV. MEASUREMENT OF RESIDENTS' INCOME GAP BETWEEN REGIONS, 2005-2016

\begin{tabular}{|c|c|c|c|c|c|}
\hline \multirow{2}{*}{ years } & \multirow{2}{*}{$\begin{array}{l}\text { Total Theil } \\
\text { Index }\end{array}$} & \multicolumn{2}{|c|}{ Interval theil index } & \multicolumn{2}{|c|}{ Theil Index } \\
\hline & & Index value & contribution & Index value & contribution \\
\hline 2005 & 0.187 & 0.131 & $69.87 \%$ & 0.056 & $30.13 \%$ \\
\hline 2006 & 0.185 & 0.129 & $69.57 \%$ & 0.056 & $30.43 \%$ \\
\hline 2007 & 0.171 & 0.121 & $70.67 \%$ & 0.050 & $29.33 \%$ \\
\hline 2008 & 0.165 & 0.118 & $71.91 \%$ & 0.046 & $28.09 \%$ \\
\hline 2009 & 0.160 & 0.115 & $71.51 \%$ & 0.046 & $28.49 \%$ \\
\hline 2010 & 0.155 & 0.109 & $70.31 \%$ & 0.046 & $29.69 \%$ \\
\hline 2011 & 0.146 & 0.103 & $70.75 \%$ & 0.043 & $29.25 \%$ \\
\hline 2012 & 0.136 & 0.097 & $71.01 \%$ & 0.040 & $28.99 \%$ \\
\hline 2013 & 0.142 & 0.107 & $75.85 \%$ & 0.034 & $24.15 \%$ \\
\hline 2014 & 0.139 & 0.105 & $76.03 \%$ & 0.033 & $23.97 \%$ \\
\hline 2015 & 0.137 & 0.105 & $76.43 \%$ & 0.032 & $23.57 \%$ \\
\hline 2016 & 0.136 & 0.104 & $76.22 \%$ & 0.032 & $23.78 \%$ \\
\hline
\end{tabular}

As can be seen from the data in Table 4, from 2005 to 2016, the overall Theil index of China's regional income gap showed a gradual downward trend. Specifically, the total Theil index shows a downward trend, from 0.187 in 2005 to 0.136 in 2012. In terms of specific values, the interval Theil index fell from 0.131 in 2005 to 0.097 in 2012, and then rose to 0.107 in 2013, and then showed a downward trend until 0.104 in 2016. The 0.056 in 2005 has dropped to 0.032 in 2016, but the rate of decline has greater volatility. It can be seen from this that the change trend of the total Theil index is consistent with the change trend of the interval Theil index. From the perspective of contribution, the contribution of the interval Theil index is relatively large, at more than $69 \%$, and the contribution rate is constantly increasing, while the contribution rate of the Theil index in the region has been declining. Specifically, the contribution of the interval Theil index in 2005 was $69.87 \%$, reached $71.91 \%$ in 2008 , and fell to $70.31 \%$ in 2010 . Then the contribution of the interval Theil index increased rapidly until 76.22 in 2016. The decline in the Theil index has hardly rebounded from $30.13 \%$ in 2005 to $23.78 \%$. From the above analysis, it can be seen that the contribution of China's regional income gap is much higher than that of the regional income gap, indicating that changes in China's regional income gap are mainly caused by changes in the regional income gap.

\section{Empirical test}

Based on the above theoretical and current analysis, this section will build an empirical test model to explore the impact of China's population migration on the income gap between regions.

\section{A. Variable selection and model building}

\section{1) Variable selection}

The article combines the previous research methods and selects the following indicators as the variables in the empirical study. At the same time, in order to increase the scientificity of the empirical results, another control variable is added to analyze its impact on the regional income gap in China.
Explained variable: This article uses the logarithmic dispersion of regional per capita income to represent the regional income gap GAP. Deviation is the absolute value of the difference between the sample data and the sample average. The dispersion method is an important tool to measure the internal gap of the system. Ni Pengfei (2014) used the dispersion method to calculate the per capita income gap of provincial residents [11]. In this paper, the specific algorithm for calculating the dispersion of per capita income gap is as follows: suppose the annual per capita income in area $\mathrm{i}$ is $\mathrm{Y}_{\mathrm{it}}$, then the regional logarithm of per capita income dispersion $G A P_{i t}=\left|\ln Y_{i t}-\ln \bar{Y}_{t}\right| \cdot$ The main reason for choosing the above calculation method is that the panel data obtained by the above calculation method can comprehensively examine the income gap of various regions in each year to obtain more accurate empirical results.

Core explanatory variable: migration human capital investment (LM). With reference to the foregoing, this article selects the per capita consumption expenditures of transportation and communications in the national statistical yearbooks by $27.825 \%$.

Control variables: Most of the research literature on regional income gaps regard urbanization rate, industrial structure, and degree of opening to the outside as the main influencing factors. In view of this, the following indicators are selected as the control variables for empirical analysis.

- Urbanization rate (UR). Considering that the regional urbanization process will affect regional economic growth through factor flow and industrial agglomeration and other factors, it will affect the regional income gap. The role. Chen Chen et al. used this indicator when studying the income gap between regions. The urbanization rate indicator UR is measured by the proportion of urban population in each region to the total population of the region over the years [13].

- Industrial structure (IND). A large number of literature studies have shown that different industrial structures will have a certain impact on residents' employment and wage levels, which in 
turn will affect the income gap. The effect of the tertiary industry on employment and income is more obvious. Shenghua Wang (2017) used industrial structure indicators when studying public input, human capital, and household income. This paper uses the ratio of the output value of the tertiary industry to the regional GDP to measure the industrial structure [12].

- Economic openness (XM). This article uses the ratio of the total import and export trade of the region to the GDP to measure the degree of economic openness. Foreign trade is the main driving force of economic growth. There is a clear regionality in China's foreign trade development. The study of the gap between foreign trade and income has attracted the attention of many scholars.

In terms of data sources, the above data comes from "China Statistical Yearbook" and provincial statistical yearbooks. Some provinces lack human capital investment data for individual years. The missing data is estimated using the moving average method. The data time span is from 2005 to 2016.

\section{2) Model building}

Considering that panel data can better combine time series data and cross-section data, it can more effectively reflect the laws and characteristics of variable changes in cross-section and time two-dimensional space, as well as pure time series data and pure cross-section data. It has many advantages, such as expanding sample size, controlling individual heterogeneity and endogeneity, increasing the degree of freedom, and improving the effectiveness of parameters. The empirical data in this chapter uses panel data from eight major regions in China from 2005 to 2016 for research The impact of resident human capital investment on China's regional income gap. Based on the previous research results, the panel data measurement model is set up as follows:

$$
G A P_{i t}=\alpha_{i}+\beta_{l} \ln \left(L M_{i t}\right)+\beta_{2} E U_{i t}+\beta_{3} I N D_{i t}+\beta_{4} X M_{i t}+
$$

$\mu_{i t}$

In order to cope with the possibility of heteroscedasticity in the time series of each variable and reduce the large-scale vibration of the model results caused by data problems, the logarithm of the investment variable of migrating human capital is adopted. Among them, GAP it represents the income gap between regions, $\beta_{i}$ refers to the elastic coefficients of these explanatory variables, $\mathrm{LM}_{\mathrm{it}}$ represents the migration of human capital investment, $\mu_{\mathrm{it}}$ is the random disturbance term, $\mathrm{i}$ represents the eight selected regions of China, and $t$ represents the time dimension.

TABLE V. DESCRIPTIVE STATISTICS OF VARIABLES

\begin{tabular}{cccccc}
\hline Variable & $\begin{array}{c}\text { Number of } \\
\text { observations }\end{array}$ & Mean & Maximum & Minimum & $\begin{array}{c}\text { Standard } \\
\text { deviation }\end{array}$ \\
\hline GAP & 96 & 0.264434 & 0.5056 & 0.0247 & 0.14547 \\
LN(LM) & 96 & 1.906169 & 2.229236 & 1.578236 & 0.164807 \\
EU & 96 & 0.51365 & 0.7052 & 0.3294 & 0.101255 \\
IND & 96 & 0.414172 & 0.539504 & 0.32786 & 0.04763 \\
XM & 96 & 0.054127 & 0.1684 & 0.0083 & 0.049236 \\
\hline
\end{tabular}

\section{B. Empirical analysis}

1) Stationarity test
TABLE VI. ADF UNIT ROOT TEST RESULTS FOR EACH VARIABLE

\begin{tabular}{ccc|ccc}
\hline $\begin{array}{c}\text { The } \\
\text { sequence } \\
\text { itself }\end{array}$ & $\begin{array}{c}\text { Include } \\
\text { intercept } \\
\text { term }\end{array}$ & $\begin{array}{c}\text { Including } \\
\text { intercept } \\
\text { term and } \\
\text { trend term }\end{array}$ & $\begin{array}{c}\text { First order } \\
\text { difference }\end{array}$ & $\begin{array}{c}\text { Include } \\
\text { intercept } \\
\text { term }\end{array}$ & $\begin{array}{c}\text { Including } \\
\text { intercept } \\
\text { term and } \\
\text { trend term }\end{array}$ \\
\hline GAP & 14.1532 & 20.9300 & GAP & $49.1378^{* * *}$ & $35.9034^{* * *}$ \\
LN(LM) & 9.8831 & 9.5003 & LN(LM) & $48.1228^{* * *}$ & $39.4459^{* * *}$ \\
EU & 3.1003 & 14.8888 & EU & $42.1892^{* * *}$ & $26.6222^{* *}$ \\
IND & 0.7214 & 1.0717 & IND & $25.733^{*}$ & $41.6424^{* * *}$ \\
XM & 9.6047 & 11.1961 & XM & $42.7263^{* * *}$ & $31.5012^{* * *}$ \\
\hline
\end{tabular}

Note: $*, * *$, and ${ }^{* * *}$ represent rejection of the null hypothesis at $10 \%, 5 \%$, and $1 \%$ significance levels, respectively

Before using the regression method to analyze the selected variables, you need to judge the stability of the time series of all variables. This paper empirically selects the ADF unit root test method to test whether each variable is stable. It can be seen from Table VI that when the unit root test is performed on the sequence itself, the variables in the model basically have unit roots, indicating that each variable is a non-stationary sequence. However, after first-order difference of variables, we can find that there is no unit root for each variable at the $10 \%$ significance level, and each variable is a stationary sequence.

2) Panel model regression results

In addition, after the Hausman test, it should be established that a fixed effect regression model should be established. The specific regression results are shown in TABLE VII.

TABLE VII. REGRESSION ANALYSIS RESULTS

\begin{tabular}{ccccc}
\hline Variable & Coefficient & Std. Error & t-Statistic & Prob. \\
\hline C & 0.486116 & 0.055600 & 8.743102 & 0.0000 \\
LN(LM) & 0.052286 & 0.076057 & 0.687450 & 0.0494 \\
EU & -0.882964 & 0.220715 & -4.000478 & 0.0001 \\
IND & 0.230129 & 0.123884 & 1.857612 & 0.0667 \\
XM & 0.681261 & 0.287179 & 2.372252 & 0.0200 \\
\hline
\end{tabular}

Among them, the regression results $\mathrm{R}^{2}=0.975862$, the higher the value, the better the model fit, followed by $\mathrm{F}=$ $308.7218, \mathrm{P}=0.0000$, indicating that the model regression results are significant. The above data shows that the regression results of the model are acceptable.

From the perspective of each variable, the following analysis results can be drawn:

In terms of explanatory variables, the elasticity coefficient of migration investment is 0.052286 , which means that for every $1 \%$ increase in migration investment per capita, the income gap between regions will increase by $0.05 \%$. It can be found from this that population migration is an important factor in the expansion of residents' income gap. In terms of control variables, urbanization will reduce the income gap between regions, and the industrial structure and opening degree will widen the income gap between regions. Specifically, the elasticity coefficient of the urbanization rate is -0.882964 . For every $1 \%$ increase in the urbanization rate, the income 
gap between regions will shrink by $0.88 \%$. The elasticity coefficient of the industrial structure is 0.230129 , which means that for every $1 \%$ increase in the proportion of tertiary industry, the income gap between regions will expand by $0.23 \%$. The degree of openness to the outside world also has a positive effect on the income gap between regions, that is, the higher the degree of openness, the greater the income gap between regions. When the degree of opening to the outside world increases by $1 \%$ at a significant level of $5 \%$, the income gap between regions will expand by $0.68 \%$.

\section{Conclusions and policy recommendations}

In summary, this article draws the following conclusions: (1) The scale of population migration in China is increasing. The direction of population migration is still mainly from west to east, from economically backward areas to economically developed areas, but some new features have also appeared, such as the phenomenon of return and diversification of migration directions. (2) The income gap of residents is mainly reflected in the income gap between regions. (3) Population migration has a longterm significant positive effect on income gap. Under the influence of the Matthew effect and the siphon effect, residents' investment in migration will increase, and the income gap between regions will also increase. Therefore, guiding population migration in a reasonable and orderly manner and narrowing the income gap between regional residents is of great significance to China's economic development and social harmony.

In order to narrow the income gap between residents in the region, the migration migration investment can be started from the following two directions. One is to strengthen the policy preference for backward areas. Both rural revitalization and urbanization can promote economic development in backward areas, increase employment opportunities, increase residents' income, and reduce population migration. The second is to build a more convenient transportation and communication network, closely connecting backward areas and developed areas, promote the full flow of various resources, reduce the cost of migration caused by transportation and communication costs, and increase the income level of residents.

\section{REFERENCES}

[1] Schultz, T, w., 1961: Investment in Human Capital, The American Economic Review, Vol. 15, No. 1.

[2] Miyagiwa K . Scale Economies in Education and the Brain Drain Problem[J]. International Economic Review, 1991, 32(3):743-759.

[3] Whalley J, Zhang S. A numerical simulation analysis of (Hukou) labour mobility restrictions in China [J]. Journal of Development Economics, 2007, 83 (2): 0-410.

[4] Konstantinos Pouliakas, Deborah Roberts, Eudokia Balamou, Dimitris Psaltopoulos. Modelling the Effects of Immigration on Regional Economic Performance and Wage Distribution: A Computable General Equilibrium(CGE)Analysis of three European Union Regions[J]. Regional Studies, 2014, 48(2).

[5] Lianqing Peng, Sarah Swider. Migration and regional inequality: changing characteristics of China 's economic inequality [J]. Eurasian Geography and Economics, 2017, 58 (1).

[6] Fan Hongzhong, Li Guoping. Capital and population mobility and their externalities and regional economic differences [J]. World Economy, 2003 (10): 50-61 + 80.
[7] Wang Wei, Zhang Zongyi, Xu Kailong. Research on the effect of labor migration on income distribution-Taking Chongqing as an example [J]. Population Research, 2007 (06): 55-66.

[8] Zhao Hai, Peng Daiyan. Empirical Analysis of Rural Human Capital Investment and Wage Income Growth [J]. Agricultural Technology and Economy, 2009 (04): 53-61

[9] Duan Pingzhong. Analysis of the influence of the difference in education level of China 's inter-provincial migrants on economic growth and regional disparities [J]. Journal of China University of Geosciences (Social Science Edition), 2013, 13 (03): 115-121.

[10] Shao Yihang, Wang Yujuan, Liu Yanan. Labor mobility and income gap evolution: based on the theory and empirical study of Chinese cities [J]. Economist, 2016 (01): 33-41.Guan Aiping, Ge Siyu. The influence of labor mobility on the regional income gap: 2000-2015 [J]. Humanities Magazine, 2017 (10): 54-61.

[11] Ni Pengfei, Liu Wei, Huang Sihe. Stock market, capital space allocation and coordinated development of regional economyBased on the research perspective of space economics [J]. Economic Research, 2014, 49 (05): 121-132.

[12] Chen Chen, Zhong Weizhou. Empirical analysis of human capital, education grade and regional income gap [J]. East China Economic Management, 2018, 32 (08): 80-87.

[13] Wang Shenghua. Public input, human capital and resident income: evidence from provincial panel data $[\mathrm{J}]$. Journal of Zhongnan University of Economics and Law, 2017 (04): 68-74 + 159-160. 